\title{
Monitoring Cuaca Berbasis Raspberry dengan Menggunakan Modul Lora
}

\author{
Saeful Bahri ${ }^{1}$, Andia Ridho Arif ${ }^{2}$ \\ 1) 2) Teknik Elektro Universitas Muhammadiyah Jakarta \\ Jl. Cempaka Putih Tengah 27 No 47 \\ Email: ${ }^{1)}$ saefulb@ftumj.ac.id, ${ }^{2)} @$ ftumj.ac.id
}

\begin{abstract}
ABSTRAK
Cuaca merupakan faktor penting untuk kegiatan manusia dalam beraktivitas setiap hari oleh karena itu dibutuhkan pengamatan unsur cuaca. Dari pengamatan unsur cuaca tersebut kita dapat mendapatkan informasi cuaca yang terjadi di wilayah tersebut sehingga masyarakat dapat mengetahui keuntungan maupun kerugian yang terjadi dengan kondisi cuaca tersebut. Saat ini masih terbatasnya alat monitoring cuaca di masyarakat terutama pada wilayah yang tidak terjangkau internet. Oleh sebab itu pada penelitian ini dibuat sistem monitoring cuaca yang mengukur suhu,kelembapan,tekanan udara,arah angin dan deteksi hujan dengan menggunakan protokol nirkabel Lora, Lora merupakan protokol nirkabel yang memiliki jarak jangkau lebih jauh dalam pengiriman data dibandingkan dengan teknologi nirkabel lainya sehingga cocok ditempatkan pada wilayah yang tidak terjangkau internet. Pada pengujian kinerja sistem monitoring cuaca ini Lora mampu mengirimkan data pada kondisi LOS sebesar 899 meter sedangkan pada kondisi NLOS sebesar 174 meter.
\end{abstract}

\section{Kata Kunci : Cuaca,Raspberry PI, Arduino, Lora,Mikrokontroler}

\begin{abstract}
Weather is an important factor for human activities in daily activities, therefore it is necessary to observe the weather element. From the observation of the weather elements, we can get weather information that occurs in the area so that people can find out the advantages and disadvantages that occur with these weather conditions. Currently there are limited weather monitoring tools in the community, especially in areas that are not covered by the internet. Therefore, in this study a weather monitoring system that measures temperature, humidity, air pressure, wind direction and rain detection is created using a wireless protocol using Lora, Lora is a wireless protocol that has a longer range in data transmission compared to other wireless technologies. so it is suitable to be placed in areas that are not covered by the internet. In testing the performance of this weather monitoring system, Lora was able to transmit data in LOS conditions of 899 meters while in NLOS conditions it was 174 meters.
\end{abstract}

Keyword: weather, raspberry pi, arduino, lora, microcontroller

\section{PENDAHULUAN}

Pengamatan unsur cuaca sangat dibutuhkan oleh masyarakat untuk berbagai keperluan. Pengamatan unsur cuaca dapat menjadi bahan acuan untuk memprakirakan dan menentukan cuaca saat itu yang sedang terjadi di wilayah tersebut dan memprakirakan cuaca yang sedang terjadi maupun cuaca yang akan datang. Data parameter cuaca ini sangat berguna untuk mengetahui klimatologis pada suatu wilayah, sehingga masyarakat setempat dapat memanfaatkan hasil dari pengamatan cuaca tersebut sesuai dengan kebutuhan masing-masing pihak yang diuntungkan dari kondisi cuaca di wilayah tersebut [1]. Dalam pemantauan cuaca, instrumen monitoring cuaca yang diletakan pada suatu lokasi tertentu untuk mewakili kondisi cuaca di daerah tersebut yang disebut stasiun cuaca. Stasiun cuaca merupakan suatu alat instrumentasi yang digunakan untuk mengukur dan mencatat parameter cuaca dengan menggunakan sensor sensor yang berkaitan dengan unsur cuaca seperti suhu,kelembapan,tekanan udara,kecepatan angin,hujan dan lainya kemudian hasil pengamatan dari pengukuran tersebut laporanya dikirim ke pusat data. Untuk membuat instrumen monitoring cuaca dibutuhkan mikrokontroler yang terhubung dengan masing-masing sensor unsur cuaca. Mikrokontroler adalah sebuah sirkuit elektronik yang telah dilengkapi dengan mikroprosesor, memory, dan antar muka input maupun output [2]. Penggunaan mikrokontroler banyak digunakan pada peralatan elektronik seperti untuk pengendalian dan pengukuran pada berbagai peralatan rumah tangga, industri dan lain - lain. Dalam pengamatan cuaca sensor-sensor ditempatkan pada suatu daerah yang dalam jangkauan WIFI untuk memproses hasil pantauan cuaca di daerah tersebut. Data yang didapat dari sensor- sensor tersebut, yang kemudian akan dikirimkan melalui perangkat WIFI yang terhubung ke web server [1]. Namun demikian, 
RESISTOR (Elektronika Kendali Telekomunikasi Tenaga Listrik Komputer) Vol. 4 No. 1 e-ISSN : 2621-9700, p-ISSN : 2654-2684

kendala yang sering muncul yaitu bagaimana jika mengukur cuaca tersebut pada suatu daerah yang tidak memiliki akses internet hal ini mengakibatkan jarak dan keadaan geografis menjadi permasalahan, Sehingga metode pengukuran telemetri dapat dijadikan solusi [3].

Ada beberapa teknologi nirkabel yang digunakan saat ini seperti teknologi komunikasi nirkabel RF 433 yang memiliki jarak jangkau maksimal 200 meter pada ruang terbuka dan dibawah 100 meter pada ruang tertutup[3] lalu ada Xbee yang memiliki jarak maksimal 30 meter pada ruang tertutup [4] dari permasalahan tersebut dalam penelitian ini penulis menggunakan modul Lora yang sedang banyak digunakan kalangan IoT saat ini karena memiliki jangkauan yang lebih jauh, Untuk jangkauan nya LoRa memiliki keunggulan yang lebih jauh dari teknologi nirkabel lainya yaitu dapat mencapai hingga 400 meter [5] sedangkan untuk ruang terbuka dapat mencapai hingga 2000 meter [6] sehingga dapat diaplikasikan ke wilayah yang terpencil yang tidak terjangkau internet.

LoRa (Long Range) adalah teknologi komunikasi nirkabel low-power spread spectrum. Karakteristik lain dari LORA adalah daya tembusnya, sehingga dapat mencakup area yang relatif luas,ada beberapa teknologi komunikasi nirkabel yang sering digunakan diantaranya yaitu Bluetooth, RFID, Wifi, dan ZigBee berikut perbandingan beberapa teknologi komunikasi nirkabel [7].

Tabel 1 Perbandingan Lora dengan modul lain

\begin{tabular}{|c|c|c|c|c|}
\hline No & Teknologi & $\begin{array}{c}\text { Jarak } \\
(\mathrm{m})\end{array}$ & $\begin{array}{c}\text { Max.R } \\
\text { ate }\end{array}$ & $\begin{array}{c}\text { Konsumsi } \\
\text { Daya }\end{array}$ \\
\hline 1 & Bluetooth & $2 \mathrm{~m}$ & $2 \mathrm{MB} / \mathrm{s}$ & Low \\
\hline 2 & WiFi & $0-60 \mathrm{~m}$ & $\begin{array}{c}54 \\
\mathrm{MB} / \mathrm{s}\end{array}$ & High \\
\hline 3 & RFID & $0-100 \mathrm{~m}$ & $\begin{array}{c}10 \\
\mathrm{~KB} / \mathrm{s}\end{array}$ & Low \\
\hline 4 & Zigbee & $0-1500$ & $\begin{array}{c}250 \\
\mathrm{~KB} / \mathrm{s}\end{array}$ & Low \\
\hline 5 & LoRa & $0-15 \mathrm{~km}$ & $\begin{array}{c}600 \\
\mathrm{~KB} / \mathrm{s}\end{array}$ & Low \\
\hline
\end{tabular}

Dapat dilihat bahwa teknologi komunikasi menggunakan LORA memiliki jarak jangkau yang cukup jauh dibanding dengan teknologi komunikasi yang lain dan mempunyai konsumsi daya yang rendah. Akan tetapi pada teknologi LORA memiliki kekurangan yaitu nilai maximum rate masih jauh dibanding dengan teknologi WiFi.

Untuk menampilkan data hasil pengamatan cuaca. Web server digunakan untuk dijadikan sarana menampilkan data secara real time yang bisa diakses oleh masyararakat yang memerlukan informasi cuaca dari hasil pengamatan tersebut. Dalam penelitian ini penulis menggunakan Thingspeak sebagai web server dalam menampilkan data hasil pengukuran. Thingspeak adalah platform IoT yang hasil pengukuranya berupa grafik secara real time dan terhistori [8] sehingga masyarakat mampu memperoleh informasi dari hasil pengamatan unsur cuaca tersebut.

\section{METODOLOGI}

Dalam penelitian ini dirancang sistem monitoring cuaca yang mengukur unsur cuaca berupa suhu,tekanan,kelembapan udara,arah angin dan deteksi hujan melalui jaringan nirkabel berbasis Lora,Terdapat dua blok dalam satu sistem yaitu node dan gateway. Pada node terdapat sensor - sensor unsur cuaca yang masing - masing terhubung dengan arduino. Sensor sensor parameter tersebut sebagai input yang terhubung menggunakan kabel UART ke mikrokontroler arduino yang keluaranya berupa nilai hasil pengukuran pada sensor tersebut yang dapat dilihat melalui serial monitor arduino setelah diprogram [9]. Kemudian hasil pengukuran tersebut dikirim dengan modul lora ke gateway untuk menerima data hasil pengukuran yang diolah oleh raspberry sebagai server. Terdapat dua buah Lora yaitu pada sisi transmitter dan receiver sebagai protokol nirkabel yang yang berfungsi mengirim data hasil pengukuran pada node ke gateway . Berikut diagram blok sistem.

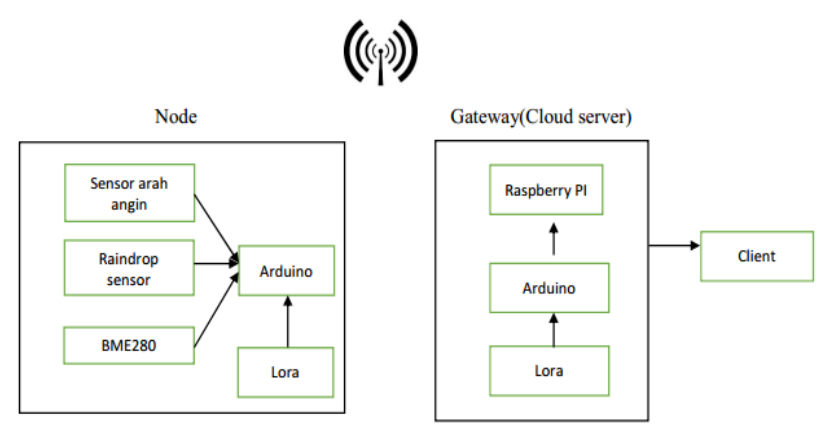

Gambar 1. Diagram blok sistem.

Dalam sistem ini suhu,kelembapan,tekanan udara,hujan dan arah angin merupakan inputan pada masing-masing sensor yang terhubung dengan sisi node,setelah diproses melalui bahasa IDE pada arduino masing masing sensor tersebut mengeluarkan 
RESISTOR (Elektronika Kendali Telekomunikasi Tenaga Listrik Komputer) Vol. 4 No. 1 e-ISSN : 2621-9700, p-ISSN : 2654-2684

nilai hasil pengukuran (output) berupa nilai hasil pengukuran yang terbaca pada serial monitor arduino. Setelah data tersebut terkumpul dalam satu paket kemudian data tersebut dikirimkan ke gateway melalui Lora transmitter untuk kemudian diterima pada sisi gateway melalui Lora receiver. Selanjutnya hasil pengukuran tersebut diolah oleh raspberry untuk kemudian hasil pengukuranya dikirimkan ke web server thingspeak untuk menampilkan data tersebut kepada client. Berikut diagram alir sistem

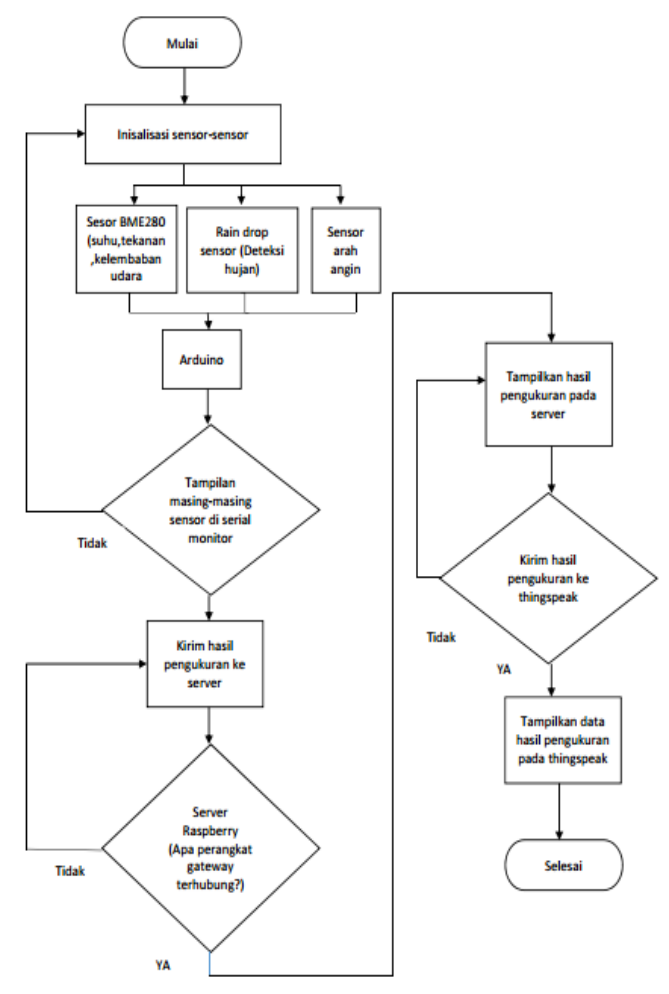

Gambar 2. Flowchart sistem

\section{HASIL DAN PEMBAHASAN}

Hasil perwujudan sistem ini, komponen Arduino uno dan lora yang sudah terhubung dengan arduino uno melalui kabel jumper diletakan pada wadah atau box. Sedangkan sensor BME 280,arah angin dan hujan diletakan di luar box karena bersinggungan langsung dengan cuaca yang akan diukur.

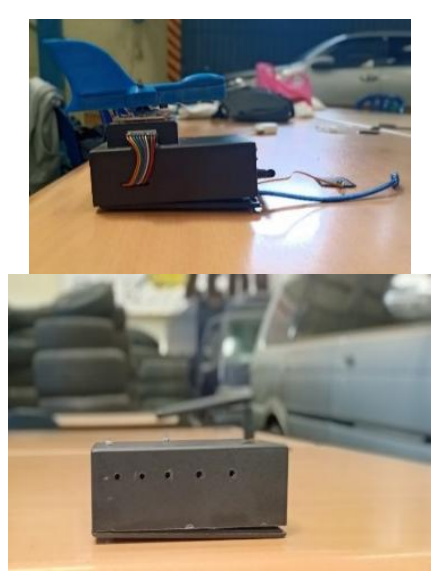

Gambar 3.Hasil perancangan node dan gateway

\section{Pengujian perangkat lunak}

Dalam pengujian perangkat lunak dilakukan dengan membuka web server thingspeak yang telah terkonfigurasi pada server raspberry.

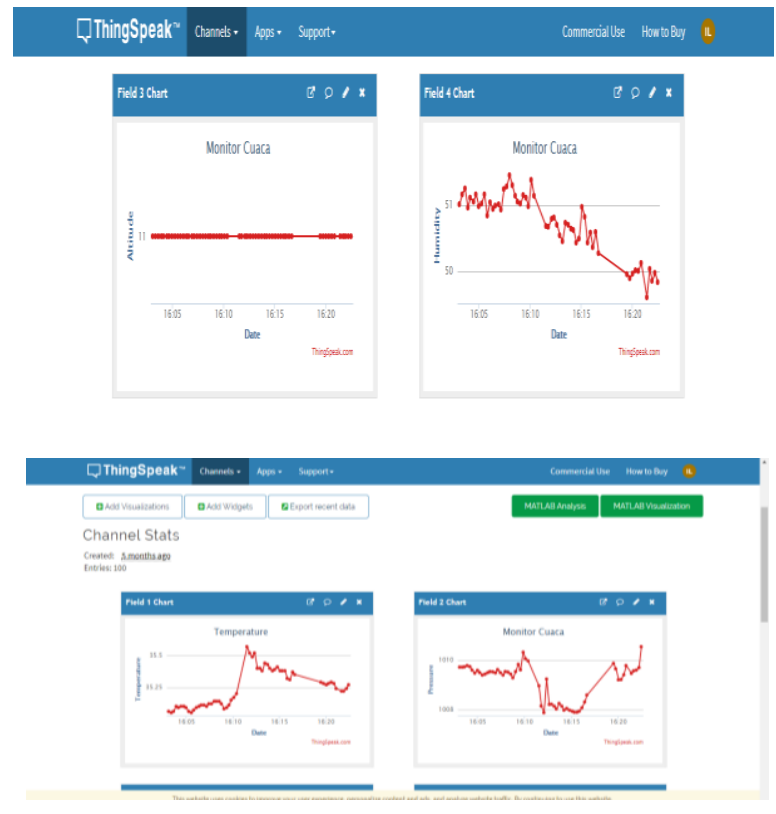

Gambar 4. Tampilan hasil pengukuran cuaca

\section{Pengujian Perangkat keras}

Pengujian Hardware antara lain pengujian jarak baik dengan cara LOS( Line of sight) dan NLOS( Non line of sight), Kemudian uji kesalahan nilai dalam monitoring dengan demikian akan diketahui ketelitian dan kesalahan alat apakah sesuai dengan yang diharapkan. Dalam pengujian hardware juga dilakukan pengujian kesalahan pengukuran yang bertujuan untuk mengetahui tingkat akurasi dan error dari data hasil pengukuran setiap sensor. Pengukuran sensor suhu, kelembababan dan tekanan udara dilakukan dengan membandingkan dengan sebuah 
RESISTOR (Elektronika Kendali Telekomunikasi Tenaga Listrik Komputer) Vol. 4 No. 1 e-ISSN : 2621-9700, p-ISSN : 2654-2684

alat digital pengukur suhu,kelembaban dan tekanan udara digital. Adapun spesifikasi alat pembanding digital dengan spesifikasi sebagai berikut:

- Altimeter: Measurement range: $-700 \mathrm{~m} \sim 9000 \mathrm{~m}$ (-2300 2950ft) (altimeter can be corrected for initial test) Resolution: 1 meters or 3 feet

- Barometer: Measurement range: 300mbar to 1100mbar Resolution: 0.1mbar.

- Thermometer: Measurement range: $10^{\circ} \mathrm{C} \sim 60^{\circ} \mathrm{C}\left({ }^{\circ} \mathrm{C}\right.$ and ${ }^{\circ} \mathrm{F}$ optional $)$ Resolution: 0.1 degrees

\section{Pengujian Sensor Suhu Udara}

Dalam pengujuan suhu udara menggunakan sensor BME 280. Setelah melakukan pengamatan dapat dilihat hasil pengamatan monitoring cuaca bersamaan dengan perbandingan pengukuran dengan menggunakan alat lain yang hasil nya sebagai berikut.

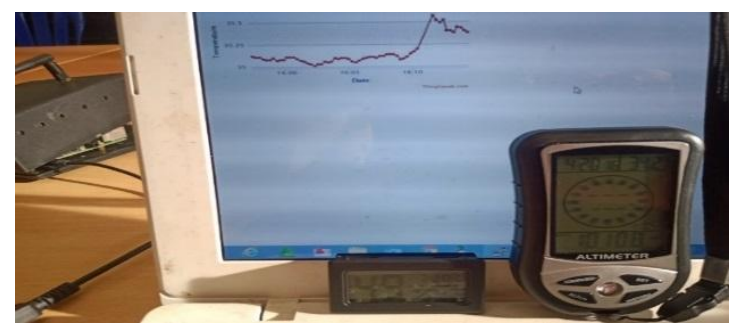

Gambar 5. Pengujian suhu udara

Berdasarkan hasil dari pengkuran suhu udara pada gambar diatas menunjukan bahwa suhu udara pada pukul 2020-04-25 16:20:02 UTC yaitu 34,28 C sedangkan pada alat pembanding sebesar 34,20 mengalami selesih sebesar 0,1 dengan persentase kesalahan sebesar $0,2 \%$.

\section{Pengujian Sensor Kelembapan Udara}

Sama seperti halnya suhu udara,kelembapan udara diukur dengan sensor BME280 dan perbandingan dengan alat lain. Berikut hasil pengamatanya.

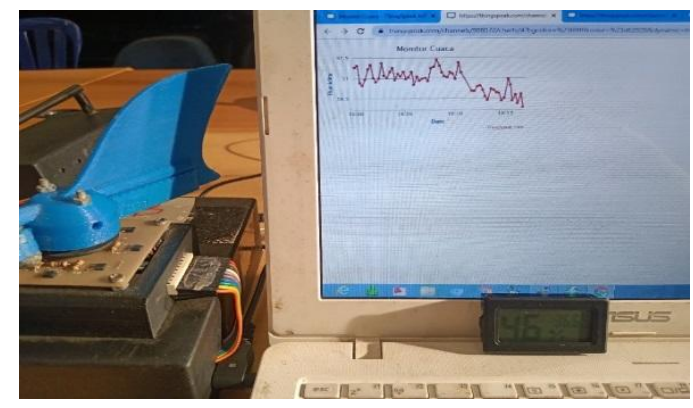

Gambar 6. Pengujian kelembapan udara.

Hasil dari pengkuran suhu udara pada gambar diatas menunjukan bahwa kelembapan pada pukul
2020-04-25 16:05:48 UTC yaitu 47,21\% sedangkan pada alat pembanding sebesar $46 \%$ mengalami selesih sebesar 1,21 dengan persentase kesalahan sebesar $2,1 \%$.

\section{Pengujian Tekanan Udara}

Tekanan udara diukur dengan sensor BME280 dan dibandingkan dengan instrumen lain. Berikut hasil pengamatanya

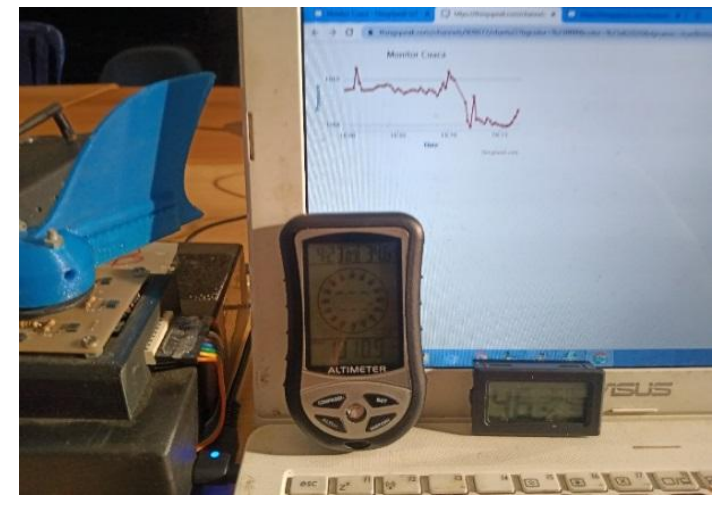

Gambar 7. Pengujian tekanan udara.

Berdasarkan hasil dari pengukuran suhu udara pada gambar diatas menunjukan bahwa tekanan udara pada 2020-04-25 16:00:55 UTC yaitu 1010,48 $\mathrm{hPa}$ sedangkan pada alat pembanding sebesar $1010,90 \mathrm{hPa}$ mengalami selesih sebesar $0,4 \mathrm{hPa}$ dengan persentase error sebesar $0,3 \%$.

\section{Pengujian Arah Angin}

Dalam pengujian arah angin diperlukan kalibrasi titik mata angin dengan cara menggunakan kompas sebagai acuan dalam menentukan titik mata angin.

Berikut pengujian arah angin.
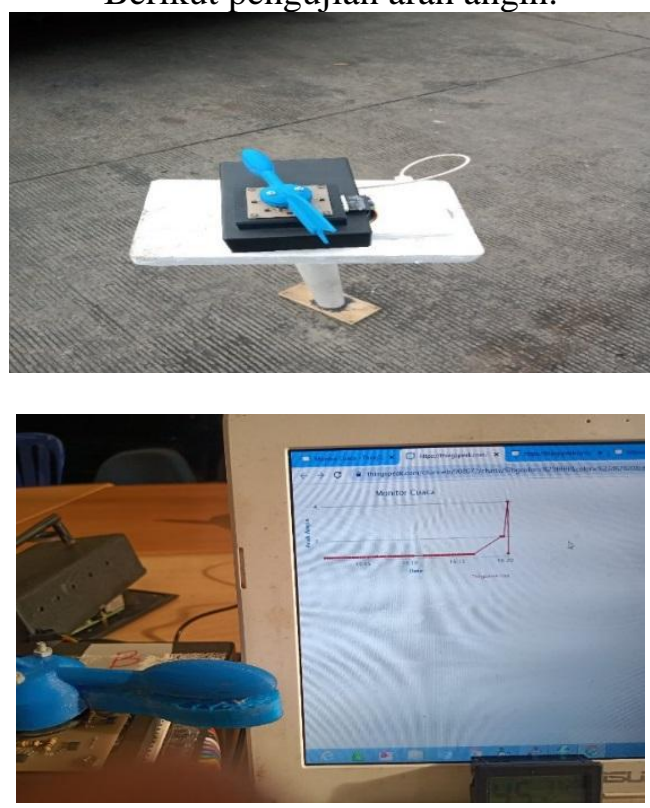

Gambar 8. Pengujian arah angin. 
RESISTOR (Elektronika Kendali Telekomunikasi Tenaga Listrik Komputer) Vol. 4 No. 1 e-ISSN : 2621-9700, p-ISSN : 2654-2684

Pada pengujian arah angin swing akan bergerak jika angin berhembus yang hasil pembacaan atah angin nya dapat terbaca melalui mikrokontroler. Pada grafik thingspeak hasil pengukuran arah angin output nya berupa angka yang telah di define pada program Arduino IDE.Berikut hasil dari pemgamatan arah angin,

Tabel 2. Pengujian arah angin

\begin{tabular}{|c|c|c|}
\hline Time & No & $\begin{array}{c}\text { Arah } \\
\text { Angin }\end{array}$ \\
\hline $2020-04-25$ 16:16:41 UTC & 1 & 1 \\
\hline 2020-04-25 16:19:45 UTC & 2 & 2 \\
\hline $2020-04-25$ 16:20:02 UTC & 3 & 4 \\
\hline
\end{tabular}

Tabel 3. Define arah angin.

\begin{tabular}{|c|c|}
\hline Define & Arah angin \\
\hline 1 & Utara \\
\hline 2 & Timur Laut \\
\hline 3 & Timur \\
\hline 4 & Tenggara \\
\hline 5 & Selatan \\
\hline 6 & Barat daya \\
\hline 7 & Barat \\
\hline 8 & Barat Laut \\
\hline
\end{tabular}

\section{- Pengujian deteksi hujan}

Pengujian deteksi yang diukur dengan raindrop sensor Menunjukan hasil sebagai berikut

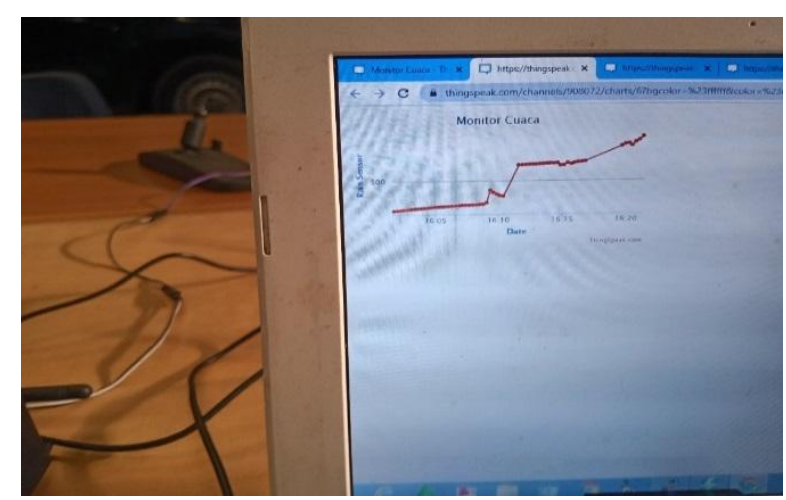

Gambar 9. Pengujian deteksi hujan

Tabel 4 Pengujian sensor hujan

\begin{tabular}{|c|c|c|}
\hline Time & No & $\begin{array}{c}\text { Rain } \\
\text { status }\end{array}$ \\
\hline $\begin{array}{c}2020-04-2515: 55: 15 \\
\text { UTC }\end{array}$ & 1 & 1023 \\
\hline $\begin{array}{c}2020-04-2515: 57: 57 \\
\text { UTC }\end{array}$ & 2 & 217 \\
\hline $\begin{array}{c}2020-04-2516: 23: 12 \\
\text { UTC }\end{array}$ & 3 & 860 \\
\hline
\end{tabular}

Dari tabel diatas bahwa raindrop sensor menunjukan nilai berupa angka. Pada program arduino rain sensor disetting pada range 0 sampai dengan 1023, Semakin kecil nilai nya maka semakin basah maka dapat disimpulkan bahwa alat dapat mendeteksi terjadinya hujan. Range pada program arduino 0 sampah dengan 600 mendeteksi terjadinya hujan. Jadi pada uji coba diatas sensor hujan tidak mendeteksi adanya air pada sensor hujan. karena nilainya 1023

\section{Pengujian Jarak}

Dalam pengujian sistem ini dilakukan dengan 2 metode yaitu pengujian pada kondisi LOS( Line of sight) dan NLOS( Non line of sight), node ditempatkan pada ketinggian yang sama yaitu 1 meter diatas permukaan tanah baik pada kondisi LOS dan NLOS. Untuk mengetahui jarak maksimal dari pengujian ini, antara node dengan gateway diuji coba dengan jarak bervariasi.

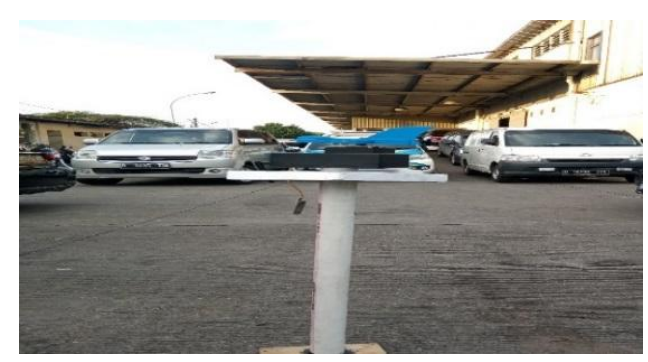

Gambar 10. Pengujian jarak.

\section{Kondisi NLOS}

Dalam pengujian ini dilakukan dengan menempatkan node dengan server dalam kondisi ada halangan sedangkan server berada pada jarak bervariasi.

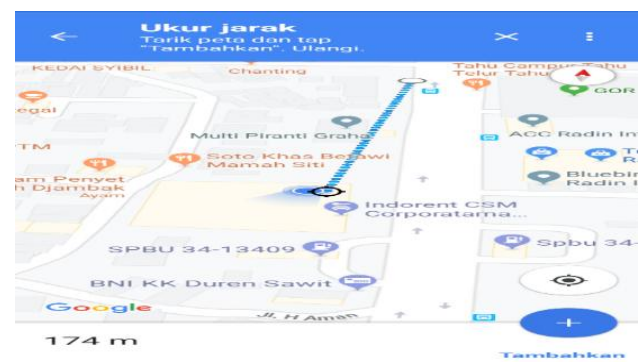


RESISTOR (Elektronika Kendali Telekomunikasi Tenaga Listrik Komputer) Vol. 4 No. 1 e-ISSN : 2621-9700, p-ISSN : 2654-2684

\section{Gambar 11. Pengujian jarak NLOS}

Dengan menggunakan titik pont pada Google maps didapatkan hasil pengukuran sejauh 174 meter antara node dengan gateway. Lebih dari itu pengiriman data ke server sudah memiliki delay.

\section{Kondisi LOS}

Dalam pengujian ini dilakukan dengan menempatkan node dengan server dalam kondisi tanpa halangan y sedangkan node di tempatkan pada jarak yang bervariasi sampai tidak ada pengiriman data ke server.

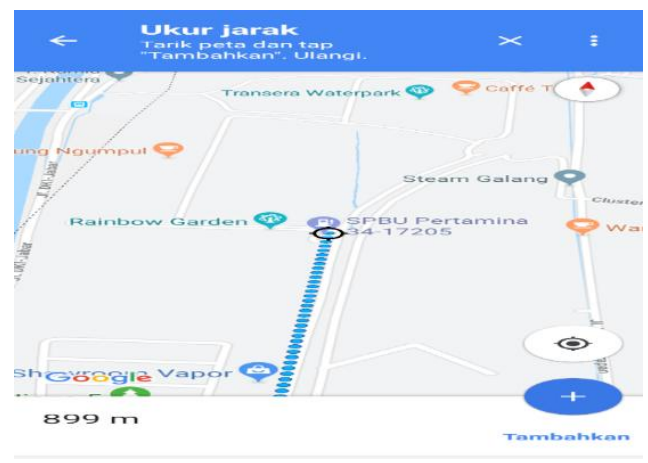

Gambar 12. Pengujian jarak LOS

Pada percobaan dengan metode LOS didapatkan hasil jangkauan pengiriman data dari node ke gateway sejauh 899 meter.

\section{KESIMPULAN}

Berdasarkan hasil pengujian yang dilakukan pada alat Monitoring Cuaca Berbasis raspberry yang dikirim melalui modul Lora maka dapat disimpulkan bahwa alat monitoring unsur cuaca berbasis raspberry dengan menggunakan modul Lora dapat bekerja sesuai dengan fungsinya. Hasil pengujian suhu udara dengan dibandingkan dengan alat ukur cuaca portable mengalami tingkat kesalahan $0,2 \%$. Hasil pengujian kelembapan udara dengan dibandingkan dengan alat ukur cuaca portable mengalami tingkat kesalahan serbesar 2,1\%. Hasil pengujian tekaanan udara dengan dibandingkan dengan alat ukur cuaca portable mengalami tingkat kesalahan sebesar $0,3 \%$. Untuk pengujian Arah angin dan hujan dapat bekerja sesuai fungsinya. Untuk pengujian jarak maksimal antara node dan gateway di dapat jarak maksimal sebesar 174 meter dengan kondisi NLOS (ada halangan) dan pada kondisi LOS sebesar 890 meter.

\section{DAFTAR PUSTAKA}

[1] W. Sucipto and W. Setiawan, "Rancang Bangun Perangkat Pemantau Cuaca Otomatis
Berbasis Mikrokontroler pada Jaringan WLAN IEEE 802.11 b," J. SPEKTRUM, vol. 4, no. 2, pp. 48-55, 2017.

[2] H. A. Rochman, R. Primananda, and H. Nurwasito, "Sistem Kendali Berbasis Mikrokontroler Menggunakan Protokol MQTT pada Smarthome," J. Pengemb. Teknol. Inf. Dan Ilmu Komput. E-ISSN, vol. 2548, p. 964X, 2017.

[3] K. Dwicahyo, H. Hariyanto, and B. Prakoso, "Telemetri nirkabel data suhu, kelembapan, dan tekanan udara secara realtime berbasis Mikrokontroler Atmega328p," J. Meteorol. Klimatol. Dan Geofis., vol. 4, no. 1, pp. 44-51, 2017.

[4] T. Alfarisi and Y. A. Pratama, "Purwarupa Sistem Pemantauan Kualitas Udara dan Cuaca Melalui Web Berbasis Wireless Sensor Network," JST J. Sains Dan Teknol., vol. 6, no. 2, pp. 248-257, 2017.

[5] A. Bhawiyuga and W. Yahya, "Sistem Monitoring Kualitas Air Kolam Budidaya Menggunakan Jaringan Sensor Nirkabel Berbasis Protokol LoRa," J. Teknol. Inf. Dan Ilmu Komput., vol. 6, no. 1, pp. 99-106, 2019.

[6] S. M. Utama, A. M. Rafi, and H. Justinus Ristoadi, "Rancang Bangun Sistem Buoy Menggunakan Sistem Komunikasi Long Range untuk Pengamatan Wilayah Pesisir," JIIF J. Ilmu Dan Inov. Fis., vol. 3, no. 1, pp. 19-25, 2019.

[7] F. A. Saputra and I. D. Wahyono, “'WATERSOR'(Waterlogging Sensor) Monitoring Genangan Air di Kota Malang Berbasis ThingSpeak Framework," in Prosiding SAKTI (Seminar Ilmu Komputer dan Teknologi Informasi), 2018, vol. 3, no. 2, pp. 165-168.

[8] K. Wang, "Application of Wireless Sensor Network based on LoRa in City Gas Meter Reading.," Int. J. Online Eng., vol. 13, no. 12, 2017.

[9] S. Bahri and K. Fikriyah, "PROTOTYPE MONITORING PENGGUNAAN DAN KUALITAS AIR BERBASIS WEB MENGGUNAKAN RASPBERRY PI," eLEKTUM, vol. 15, no. 2, 2018. 